\title{
Investigations of a vertical axis wind turbine with frontal cylindrical guide vane unit
}

\author{
Valentin Obretenov ${ }^{1, \dagger}$ and Rossen Iliev $^{1, *}$ \\ ${ }^{1}$ Department of Hydroaerodynamics and Hydraulic Machines, Technical University of Sofia, Bulgaria
}

\begin{abstract}
The paper presents the results of an experimental study of a vertical wind turbine type Darrieus with frontal cylindrical guide vane unit. The main goal of the research is to analyze the influence of the geometry of a classical cylindrical guide vane unit on the active and passive zone of the wind turbine. The aerodynamic scheme is synthesized by a classic runner and frontal cylindrical guide vanes. Three different guiding devices of a model vertical wind turbine with frontally located guide vanes have been studied. Their influence on the characteristics of the turbine has been examined. The reasons of the differences in the characteristics of the three studied variants of the guiding devices are clarified by numerical study of the flow through the blade cascades of the guide vanes and the runner. The results of the study shows what is the reason for the positive effect of the cylindrical vane guide device on the wind turbine's runner.
\end{abstract}

\section{Introduction}

The idea for this study comes from the analysis of the streamlines and velocity vectors of the airflow through vertical axis wind turbine with cylindrical guide vane device[1]. It seems that the guide vanes acts more like as deflector rather than flow directing vane cascade. The results from the previous physical experiments conducted in HEHT Lab[2] in Technical University of Sofia, showed that the density of the guide vane cascade increases significantly the power coefficient of the wind turbine. That's because the guide vanes in the active zone directs the flow to the turbine's runner and improves the absorption of the kinetic energy. On other hand the guide vanes in the passive zone, acts like an energy absorbing shield that shades the runner's blades and eliminates the production of negative torque.

The task of the study is to analyze the influence of the reflecting and directing capabilities of a frontal guide vane device on the turbine performance. The rear guide vanes are removed from the aerodynamic scheme, since they don't significantly affect the power of the wind turbine[1]. This paper presents results of studies aimed at optimizing wind turbine efficiency.

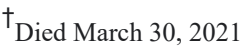

*Corresponding author: riliev@tu-sofia.bg
} 


\section{Description of the test stand and the plan of the experiment}

\subsection{Test stand}

In order to study in details the influence of the guiding vane cascade, three variants of frontal guiding devices are proposed.

First one (Fig.1) is consisted of sixteen frontally located guide vanes - 1. Their leading edge is oriented parallel to the velocity vector of the wind. Second one (Fig.2 (a)) differs only in the pitch angle of the vanes in the passive zone -2 . They are placed in such way that forms barrier. The last variant (Fig.2 (b)) is consisted of ten guide vanes mounted at their optimal pitch angle[2] and six vanes, placed in the same way as variant (b).

The axis of the guiding vanes - 1 are placed along the contour of a cylindrical surface with diameter $D_{0 g v}=1.080 \mathrm{~m}$ between two supporting static rings -5 . The vanes are part of cylindrical surface with radius of curvature $r_{l}=0.1 \mathrm{~m}$. They have chord length $l=0.115$ $\mathrm{m}$ and height $B_{0}=0.927 \mathrm{~m}$.

The runner's blades - 3 are mounted between two discs - 4 with axis placed on cylindrical surface with diameter $D_{0 r}=0.8 \mathrm{~m}$. The blades are part of cylindrical surface with radius of curvature $r_{2}=0.1 \mathrm{~m}$. They have chord length $l=0.150 \mathrm{~m}$ and height $H=0.8 \mathrm{~m}$. The construction allows the change of the pitch angle $-\varphi_{\mathrm{r}}$ in wide range. The shaft of the turbine is mounted inside the static pipe - 7. The model wind turbine and the guiding device are mounted on the platform of stand №7C[3] in square aerodynamic tunnel -6 with length of the sides $D_{t}=1.3 \mathrm{~m}$.

The wind velocity through the tunnel is generated by an axial fan driven by asynchronous electric motor[3]. It's speed is regulated by a frequency inverter which allows changing of the wind speed in wide range (up to $11 \mathrm{~m} / \mathrm{s}$ ). This completely covers the average velocities of the winds in most countries and makes the stand suitable for studying small scale wind turbines.

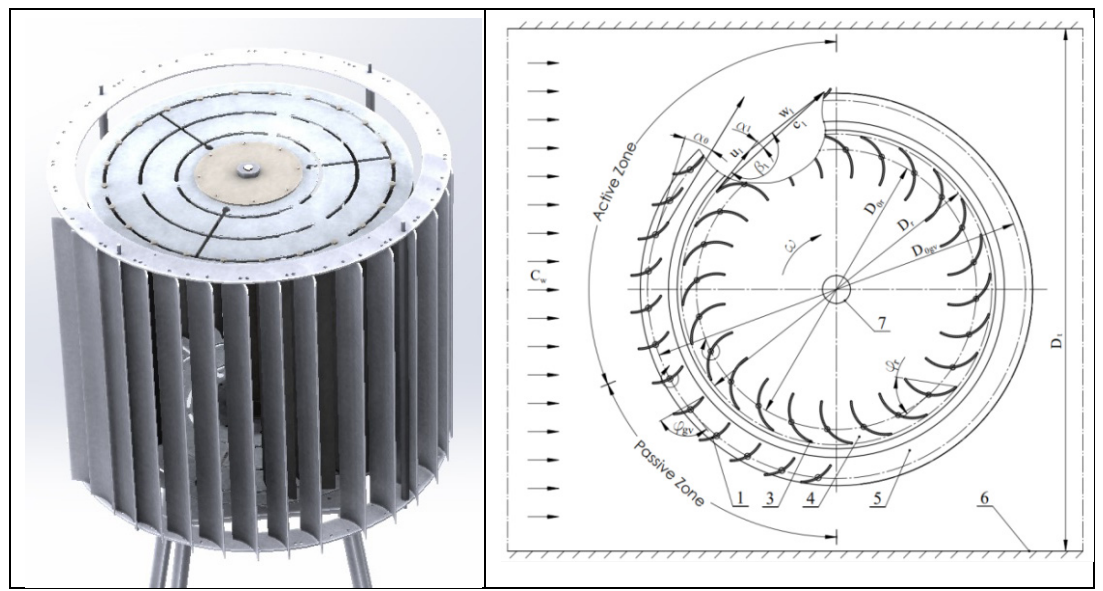

Fig. 1. Frontal guiding device (FGD) with frontal oriented guide vanes. 


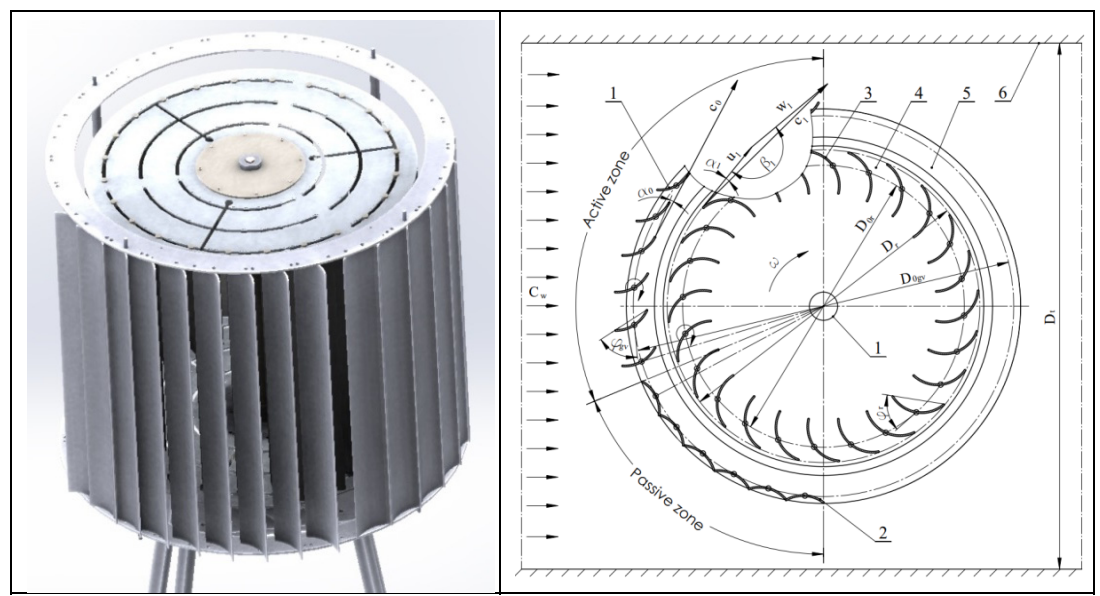

(a)

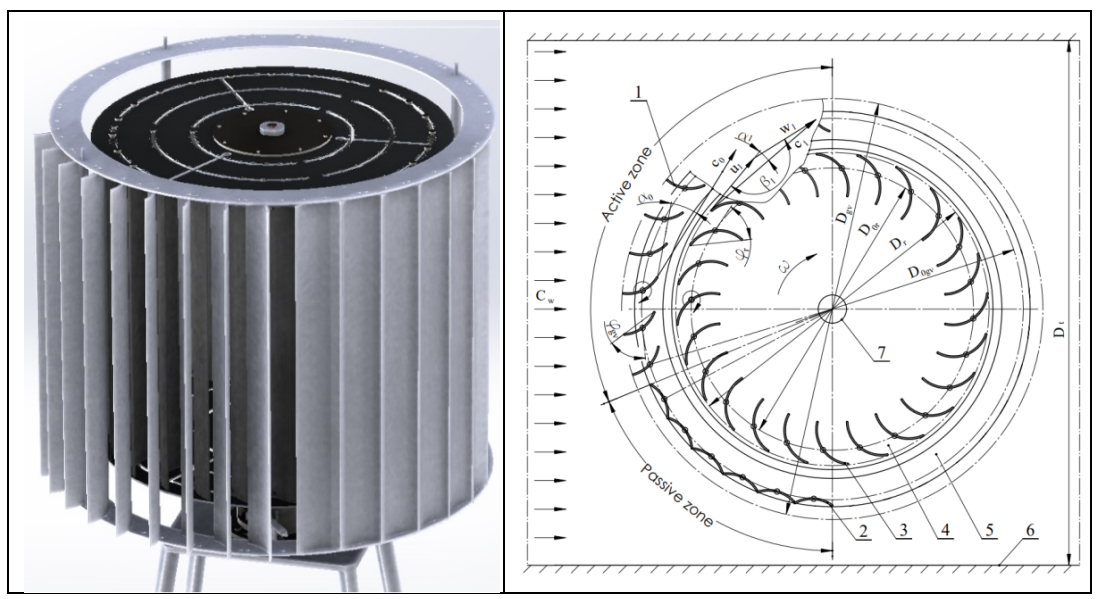

(b)

Fig.2. Frontal guiding device (FGD) with frontal oriented (a) and radial oriented (b) guide vanes in the active zone, with flipped guide vanes in the passive zone forming an absorbing shield.

\subsection{Plan of the experiment}

The study was conducted at optimal pitch angle of the guide vanes, calculated from planned physical experiment[1] and at five different pitch angles of the runner's blades around the optimal value. The objective function is the power coefficient (efficiency) $C_{p}$ of the turbine:

$$
C_{p}=\frac{P}{P_{w}}
$$


where $P$ is the effective power on the shaft of the turbine (W) and $P_{w}$ is the power of the airflow (W).

$$
\begin{gathered}
P=M_{b} \cdot \omega=M_{b \cdot} \frac{\pi \cdot n}{30} \\
P_{w}=\rho . S \cdot \frac{C_{W, S}^{3}}{2}
\end{gathered}
$$

In the above equations $M_{b}$ is the torque of the shaft (N.m), $n$ is rotating speed of the turbine $(\mathrm{rpm}), \omega$ is the angular velocity $(\mathrm{rad} / \mathrm{s}), S=D_{I r} . H$ is the transverse area of the runner $\left(\mathrm{m}^{2}\right)$, where $D_{l r}$ is the outer diameter of the runner $(\mathrm{m}), H$ is the height the working blades $(\mathrm{m})$ and $C_{w}$ is the area-averaged airflow velocity $(\mathrm{m} / \mathrm{s})$.

The operating mode of the wind turbine is changed by mechanical brake system, which regulates smoothly the load on the turbine's shaft. The torque and the rotating speed values are automatically recorded in computer by process indicator and are averaged over time by specialized software, in order to eliminate the measurement error. The study is conducted at constant air velocity $C_{w}=7 \mathrm{~m} / \mathrm{s}$, which is close to the average wind speed in the country.

The influence of the three different guiding cascades on the turbine efficiency will be determined by comparing the maximum values of the power coefficient $C_{p \max }$ for each of the five pitch angles of the working blades.

\section{Results}

The results from the physical experiments are shown on the figures below.

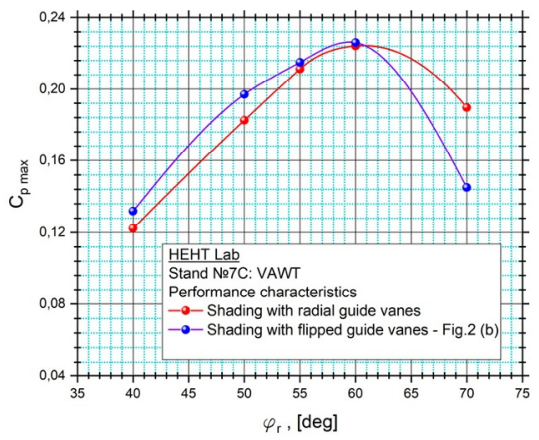

(a)

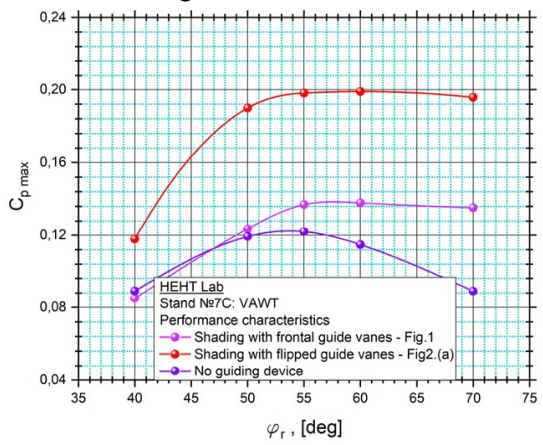

(b)

Fig.3. Characteristics of FGD with radial oriented (a) and frontal oriented (b) guide vanes.

To clarify the airflow through the three types guiding cascades was performed a numerical study with the commercial software Ansys Fluent. The dimensions and grid parameters of the computational domains corresponds to the recommended values[4,5,6]. The far field velocity is set to $7 \mathrm{~m} / \mathrm{s}$ and the environmental pressure inside the computational domains is set to $1 \mathrm{~atm}$. The used turbulent model is k-omega SST with "The Moving Frame of Reference" (MFR)[7] approach.

The calculated velocity vectors of the flow through the active and passive zones for each of three variants are shown on Figs. 4 and 5 for the optimal operational modes of the wind turbine. 


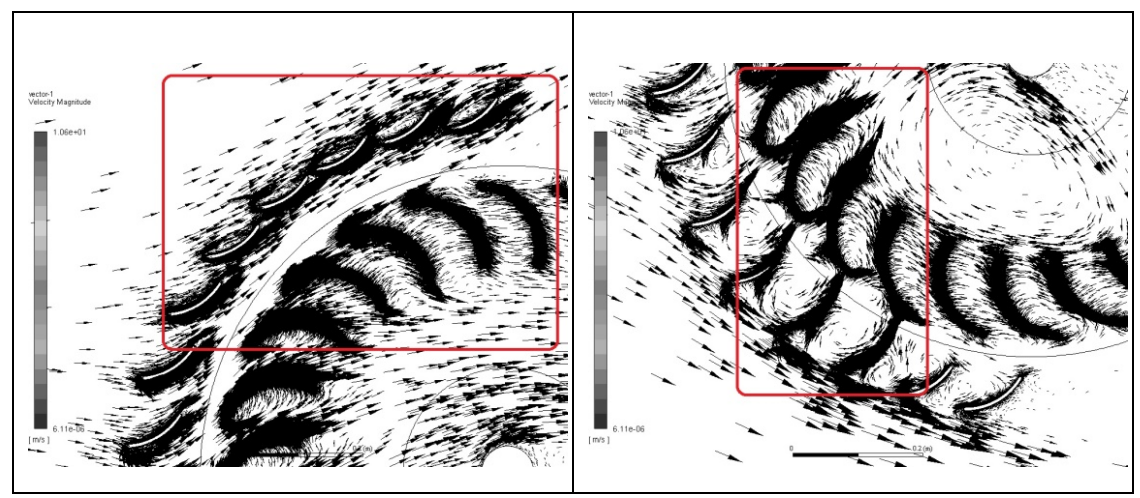

(a) Active zone

(b) Passive zone

Fig.4. Airflow velocity vectors through the guiding device with fontal oriented guide vanes (Fig.1).

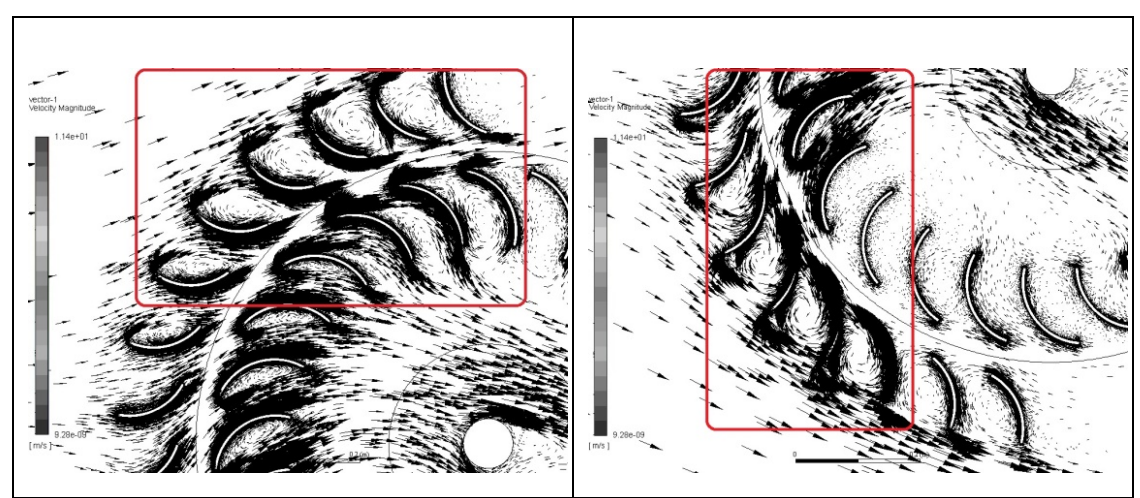

(a) Active zone (Fig.2 (a))

(b) Shading the passive zone with radially oriented vanes

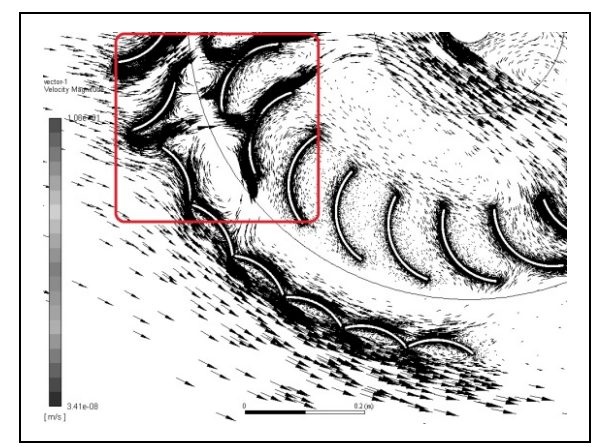

(c) Shading of the passive zone with flipped vanes that formed a barrier (Fig.2 (b)).

Fig.5. Airflow velocity vectors through the frontal guiding device (Fig.2). 
On Fig. 6 for comparison is shown the flow through the runner without guiding device.

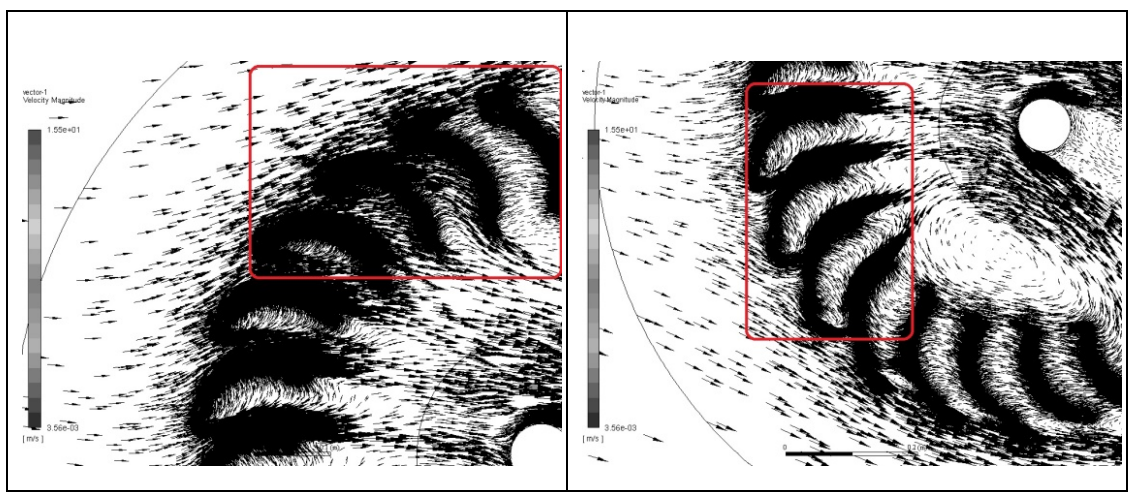

(a) Active zone

(b) Passive zone

Fig.6. Airflow velocity vectors through the turbine's runner without guiding device.

\section{Analysis}

1. Frontal guiding device with frontal oriented guide vanes increases the efficiency of the turbine up to $4.6 \%$, compared to aerodynamic scheme without guiding device (Fig.1 and Fig.3 (b)). Larger deviations of the power coefficient $C_{p}$ between these two schemes are observed at pitch angles $\varphi_{1 r}$ from $50^{\circ}$ to $70^{\circ}$, while at pitch angles less than $50^{\circ}$ the differences are insignificant. This can be explained by the fact that the guiding vanes in the active zone directs the airflow to the lower concave surface of the blades, especially at the high pitch angles. Thus, the drag force acting on the blades is increased and the blade cascade of the runner begins to work on the principle of the Savonius turbine. On other hand the shading of the passive zone with flipped guide vanes that forms barrier (Fig.3 (b)) increase the efficiency of the turbine with additional $6.4 \%$. Thus, the overall efficiency reaches $19.6 \%$. Graphs of these two guiding devices are similar and shifted relative to each other by almost $6 \%$ (except at pitch angle $40^{\circ}$ ). They have almost constant $C_{p \max }$ at range of the pitch angle $55^{\circ}-70^{\circ}$.

2. The shading of the passive zone with flipped guide vanes does not lead to significant differences in the power coefficient when using frontal guiding device with radially oriented blades (Fig.3 and Fig.6 (a),(b) and (c)). The $C_{p}$ values at the optimal pitch angle are almost the same. The only noticeable difference of $4 \%$ is at $\varphi_{\text {run }}=70^{\circ}$ in favor of the variant on Fig.2 (b).

3. The frontal vanes (Fig. 1, Fig.4 (b)) lead part of the airflow in the passive zone, which partially decreases the negative torque. This explains why the power coefficient of turbine without guiding device is almost the same as the power coefficient of the turbine with frontal oriented guide vanes at pitch angles $40^{\circ}$ $50^{\circ}$.

4. The guide vanes placed radially at their optimal pitch angle directing the airflow to the active zone of the runner against the lower concave side of the blades - Fig.5 (a). The wind is repelled from the passive zone - Fig.5 (b). This improves the absorption of the kinetic energy and removes the production of negative torque at 
the same time. When we flip the guide vanes in the passive zone (Fig.5 (c)) the repulsive effect is the same. This explains why there is no significant difference in the power coefficient between these two aerodynamic schemes (Fig.3 (a)).

5. In absence of guiding device the airflow attacking the runner blades at different angles, which decrease the effective power of the turbine - Fig.6. As a result of the free uncoordinated airflow, increased vortices are observed around the blades in the active and passive zone of the runner. The removed barrier in the passive zone of the wind turbine allows the airflow to attack freely the upper convex surface of the blades, which generates negative torque and decrease the power of the turbine's shaft.

\section{Conclusions}

- The reflection of the flow from the passive zone of the vertical wind turbine is the leading factor that increasing its efficiency. The directing of the flow in the active zone also increases the power coefficient but the benefits are 2.5 times lower.

- The classical cylindrical guiding device owes its high efficiency to the shading of the passive zone.

- Despite the existence of a number of alternative devices, the classical cylindrical guide vane unit is one of the most suitable options, as it does not create much frontal resistance and allows the airflow to pass through the vane cascade without huge volume losses.

- The high values of $C_{p}$ for this type of wind turbines gives grounds for conducting more in-depth research in the field of frontal guiding devices in order to increase their efficiency.

- The use of frontal guiding device would justify the investments if is achieved independence from the wind direction relative to the periphery of the runner.

\section{References}

1. V. Obretenov, R. Iliev. Determination of The Optimal Parameters of a Vertical Axis Wind Turbine with Cylindrical Guide Vane Unit. 6th International Symposium on EFEA, Technical University of Sofia, (2021).

2. V. Obretenov, Ts. Tsalov. The new hydraulic laboratory at the Technical University of Sofia. Collection of scientific papers of the IX international scientific and technical conference ,, Hydraulic machines, hydraulic drives and hydropneumatic automation. Current status and development prospects “, p. 79-87, St. Petersburg, (2016).

3. V. Obretenov, R.Iliev. A new model vertical axis wind turbine. Proceedings of the Scientific Conference EMF'2018, vol. II, p. 288-295, Sozopol, (2018) in Bulgarian.

4. R. Iliev. CFD analys is of performance characteristics of different Darrieus turbine runners. E3S Web of Conferences, vol. 207. 25 ${ }^{\text {th }}$ Scientific Conference on PEPM, Sozopol, (2020).

5. Almohammadi, K.M., D.B. Ingham, L. Ma, M. Pourkashan. Computational fluid dynamics (CFD) mesh independency techniques. Energy, vol. 58, pp. 483-493, (2013).

6. Balduzzi, F., A. Bianchini, R. Maleci, G. Ferrara, L. Ferrari. Critical issues in the CFD simulation of Darrieus wind turbines. Renew Energy vol. 85, p. 419-435, (2016).

7. R. Franzke, S. Sebben, T. B, E. Willeson. Evaluation of the Multiple Reference Frame Approach for the Modelling of an Axial Cooling Fan. Energies, vol. 12, (2019) 